\title{
A Study on the Perception of POKM as the Organizational Knowledge Sharing Enabler
}

\begin{abstract}
Knowledge is asset to many knowledge-driven companies in a globally competitive business eco-system. Companies that are able to capture and reuse knowledge efficiently claim that higher quality products and services can be realized in lower cost and time. Researches on factors that motivate successful knowledge practices using Knowledge Management Systems (KMS) have been well investigated. However, factors on people, organization and technology may vary for organizations of different sizes in countries with different culture. In this study, the case organization failed to achieve some of the goals such as knowledge sharing among employees and creation of new skills and knowledge. This research carried out a detailed study on POKM, a tailored made KMS used by a Malaysian IT Shared Services Company. This study investigates the perception of knowledge workers toward technological characteristics of POKM. The study examines the POKM system quality, perception of POKM user interface, quality of content management offered by POKM, POKM functions, user satisfaction toward POKM and perceived POKM benefit among knowledge workers. The research investigates a IT Shared Services Company in Malaysia. Interview with knowledge workers in the organization takes place before questionnaire survey is distributed to all the participants. This paper presents an in-depth analysis on the interviewees' responses. The outcome of the interview content is used as the basis to design the questionnaire survey. The outcomes of the research show that the quality of POKM is stable, easy to use and organization of the content is rated good. However, POKM has poor response time and search capability. The content is found to be difficult to locate in the POKM but most participants agree that knowledge stored in the POKM is helpful, can be accessed anytime and anywhere and useful for their day-to-day job. As for the user interface, POKM is not very pleasant to use with a weak set of functions and features in particular social networking feature is not available. For user satisfaction towards POKM, it is shown that users are not satisfied with the efficiency and effectiveness of the systems. However, employees generally are satisfied with ease of access and download features. In term of perceived POKM benefits, users agree that POKM is an enabler for acquiring new knowledge and innovative ideas, managing and storing knowledge, and accomplishing tasks more efficiently. Lastly, knowledge users agree that POKM functions enable knowledge networking, sharing, and creation in the organization.
\end{abstract}

Keywords - POKM, Technological Factors, Knowledge workers, Knowledge management, Knowledge Sharing Enabler

\section{INTRODUCTION}

In the current competitive market setting, organizations agree that knowledge contributed by employees benefit day-to-day operations in numerous ways. Organizations need to strategically position and financially reward the knowledge practices if they want to motivate their employees to contribute and share their knowledge and expertise (Argote, 1999; Grant, 1996; Wernerfelt, 1984). In view of the importance of organizational knowledge, many organizations start to evolve and transform themselves into knowledge centric organizations where knowledge workers in these organizations manage capture, utilize and share knowledge as part of their day-to-day workflow. The advancement of information technology allows one to capture and organize dispersed organizational information into repositories for reuse to make better decisions and improve productivity with lower cost in the job. To manage knowledge, Knowledge Management Systems (KMS) are used by many organizations to better manage organizational knowledge to facilitate collaborative communication and knowledge sharing among employees. Works on many technical aspects of KMS such as ease-touse, intuitively designed user interface, pervasive platforms, and cloud are some emerging technologies that support knowledge management activity. In this research, an investigation on a tailor made KMS, POKM deployed by a IT Shared Services Company, is carried out. In this study, the quality of the system, the quality of content organization, user interface, system satisfaction, perceived system benefits and functionality are examined and concluding remarks are illustrated at the end of the paper.

\section{KNOWLEDGE MANAGEMENT SYSTEMS AND KNOWLEDGE WORKERS}

The terms Knowledge Worker and Knowledge Management Systems (KMS) have been defined and presented by many researchers and there is a small variation among these definitions. Articles on knowledge worker and knowledge management systems are reviewed in this paper to provide a comprehensive view and characteristics of these two terminologies. 


\subsection{Knowledge Workers}

The revolution of knowledge workers revolves around employees migrating from technical skilled workers to knowledge based workers. Gone were the days where employees are well needed in industrial automotive works where they perform structured and routine works which are manually operated and heavy labor intensive. Knowledge worker has become an asset for every organization based on their intellectual capital (Pasher et al., 2011; Rogoski, 1999). In today's new economy, many organizations are moving towards economy based knowledge workers. Economy based knowledge workers are to replace industrial mass production workers. The term knowledge worker was first coined and used by Peter Drucker (1954) where he predicted that knowledge workers will take over the traditional blue collared employees in 50 years to come (Drucker, 1954; Mladkova, 2011; Farkas et al, 2011). True indeed this has become a reality in many developed countries. Employees who transform themselves to be a knowledge worker are well accepted in the fast moving new economy.

Drucker (1954) defined knowledge worker as a person who has knowledge and is able to use his knowledge in the work. He also stressed that these individuals are referred to as high level employees who apply theoretical and analytical knowledge to develop new innovated products and services. $\mathrm{He}$ labeled knowledge worker as a person that is able to acquire, manipulate, interpret and apply information in order to perform multidisciplinary, complex and unpredictable work (Drucker, 1954; Knowledge Worker, 2013). In 1990, Alvin Toffler stated that a knowledge worker is an individual that must possess some forms of technological knowledge and he is able to manage the knowledge among their peers. He refers knowledge worker as a scientist, an engineer and a person who manages technology. As for Jack Vinson (2009), he qualifies a knowledge worker as somebody who uses their brains more than their hands.

Thomas Davenport (2005) defined knowledge worker as somebody who obtains good education qualification and experience. He also stressed that knowledge worker's job involves knowledge creation, sharing, and applying the knowledge on their day-to-day job operations. Furthermore, work conducted by Reboul (2006) pointed out that the importance of knowledge worker and the relationships between knowledge workers and organizations can be summarized as the following:

- Losing any knowledge workers in an organization is a loss to its intellectual capital

- Knowledge workers use tacit and explicit knowledge

- Knowledge workers require continuous learning and self-improvement

- Knowledge workers manage their days where they prefer to plan out their own agenda and work task

Spiral (2008) summarized that knowledge workers are not laborers who work as farmers in the field. They are professionals, office workers and managers. Rogoski (1999) also concluded that knowledge workers are considered as top organization asset and they are individuals who accumulate, create and disseminate knowledge in their job.

\subsection{Characteristics of Knowledge workers}

A knowledge worker is a person who is able to perform, work on complex issue, find, access recall and apply information to acquire and improve their knowledge. According to William W. Prince (2011), all knowledge workers have the following characteristics:
a. Possessing some kind of theoretical knowledge
b. Ability to find and access information
c. Able to apply the retrieved information
d. Able to communicate well
e. High motivation
f. Having intellectual capabilities. 


\subsubsection{Theoretical knowledge}

Most of the knowledge workers are knowledgeable in specific factual and theoretical information, For example a school teacher will be mastering the information of a specialized subject matter and teaching strategies whereas a sales person will customer interest in the product. Therefore it is highly noticeable that every knowledge worker must be good at theoretical knowledge.

\subsubsection{Ability to find and access information}

The need to stay competitive in a globally borderless business world demands companies to manage organizational knowledge effectively. The rapid advancement of distributed computing such as web technologies and pervasive computing have provided an economically viable and efficient platforms to manage knowledge collaboratively with all the stakeholders globally and effortlessly. With the knowledge and information continuing growing in an organization, problem may arise due to the massive amount of information where each employees need to be familiar at. Therefore knowledge worker must work independently to identify which information is needed and to be able to locate these information successfully.

\subsubsection{Able to apply the retrieved information}

Solving problems, generating ideas and preparing documentations are ways which the knowledge workers use to apply the information that they have gotten. It is crucial that knowledge workers' jobs make crucial ability to apply information to a new situation.

\subsubsection{Able to communicate well}

Knowledge workers must be able to speak, write, read and listen closely on the information. They must be able to converse well with their subordinates and their supervisors in order to achieve the organizational effectiveness and continual improvement of products and sales together.

\subsubsection{High motivation}

Knowledge worker requires having continual growth and skill development on acquiring the information. Knowledge workers must continual having the interest to find and apply the information into their work. Due to the recent rapid changes on the new technological developments, Knowledge workers must maintain their desire to apply the information and to reuse the information using the new technologies into their work.

\subsubsection{Having intellectual capabilities.}

Intellectual capabilities in acquiring skills are much needed in knowledge workers. Such capabilities include understanding, retrieving, applying, processing the information. Knowledge worker must possess intellectual capabilities such as able to locate and apply the information and to have proper communication skills.

\subsubsection{Categorization of knowledge workers}

Knowledge workers is said to be able to explain, analyze and make decisions based on their own standards operating procedures and behavior of working.

Figure 1: Classification of Knowledge Workers (KW) occupations 
Wolff (2006) classified knowledge workers based on classification of their occupations. He supported that knowledge workers are professional workers. In Figure 1, he depicts that different types of occupations such as architects, programmers, engineers and judges are grouped in different category of knowledge workers.

\subsection{Knowledge Management Systems}

Knowledge workers are able to perform well in organizations with proper utilization of KMS to capture and reuse information on their daily tasks. In order to take full advantage of organizational knowledge, KM systems implementation must be successful.

Knowledge workers tend to create, share, disseminate and reuse both tacit and explicit knowledge in their day-to-day works. Knowledge management systems could take any forms: paper-based documentation, conventional knowledge management systems, and Web 2.0 social networking and microblogging systems, to carry out their knowledge activities in organizations. The understanding of the relationships between technological aspects of KMS and knowledge activities that carried out by the knowledge workers is essential in order to nurture knowledge sharing culture in organizations.

Knowledge management was defined as a process of applying a more structured way that captures and reuses knowledge with the best practices hoping to reduce cost of work (Nonaka and Takeuchi, 1995; Pfeiffer and Sutton, 1999) in the organizations. American Productivity and Quality Center (APQC) defines knowledge management as a systematic approach and effort which convert information to knowledge and allowing it to grow, flow and create value out from it (Dell and Hubert, 2011). The main objective is to be able to capture the right knowledge, deliver it to the right people at the right time to be able to disperse the knowledge back to the community in order to improve the organizational performance. According to Dalkir (2005), Knowledge Management (KM) can be divided into three perspectives and each leads to a different definition that suits that perspective.

\subsubsection{From the business perspectives}

It is very hard to retain employees' knowledge in the organization as many suffered from brain drain issues especially when one leaves the company together with his knowledge. Knowledge had been classified as an asset (Wiig, 1993) to many organizations. According to Dalkir (2005), organizations should capture tacit and explicit knowledge concerning of the strategy, policy and practice in the organization and be reflected at all levels.

\subsubsection{From the knowledge science perspectives}

According to Wiig (1993), knowledge can be transformed in many forms such as books, magazines and newspaper. As time goes by, these transformations are accumulation of expertise. When this knowledge is used appropriately at the right time by the right people, an increase of organizational effectiveness can be observed.

\subsubsection{From the technology perspectives}

Technology is the knowledge management enabler that provides information repository. KMS provides a means to capture, share and reuse knowledge among employees in organizations. KMS also provides filtering and search functions and other customizable features to allow effective knowledge dissemination among employees. Table 1 summarizes a non-exhaustive list of KM and Knowledge Sharing systems that are commercially available.

Table 1: List of KM or KS systems 
Table 2: Features/functions in some selected KM or KS systems

Table 2 depicts a list of commonly available features/functions in some KM/KS systems (Rikard et al., 2000; Frank M., 2008).

\section{TECHNOLOGY USE IN KNOWLEDGE MANAGEMENT}

The use of technology in organizational knowledge management has been studied extensively by many researchers. Zyngier (2013) found that there is a different level of understanding on the concept of knowledge management and the role of technology in KM implementation strategies in her works. She examined 1000 Australian private and public organizations on the understanding of the concept of knowledge management and their uptake trends between March and July 2001. Her research findings showed that $85 \%$ of respondents defined knowledge management as being a business focussed approach comprising the collection of processes that govern the creation, dissemination and utilisation of knowledge to fulfil organisational objectives. Of the remaining $15 \%$ of respondents, $7 \%$ relate knowledge management to intellectual assets taking the form of documents and databases, $6 \%$ see it as a technological concept and $2 \%$ see no visible process.

Figure 2: Technologies in use

Zyngier (2013) also find that $90 \%$ of the organisations used Intranet extensively as a means to share knowledge. In Figure 2, technologies such as groupware, internet, online information sources, electronics bulletin boards, document repositories and management and intranet are found to have used extensively by Australian corporate even though there are some may have no plan at the point of data collection. Internet is the only technology that has been adopted in all organizations surveyed.

Lindvall et al. (2002) examined the technological aspect of Knowledge Management Systems in their works on the tools that support knowledge management activities in organizations. They categorize these tools into classes, based on their capabilities and functionalities; they show different type of tasks and the knowledge processing operations these tools they support. The authors summarized knowledge management tools into two models: repository-based software systems that support a majority of the phases in the knowledge life cycle and systems actually deal with the analysis and synthesis of new knowledge. They conclude that most of the KM tools are specialized tool and no tool is complete.

Borghoff et al. (1997) stressed that information technology is unarguably been used pervasively in organizations and thus qualifies as a natural medium for the management of knowledge flow. Many knowledge theorists also warn that the attitude that drives management towards strong investment in IT on the expense of human capital investment should be avoided. However, Borghoff et al. (1997) also pointed out that many research findings have shown that information technology is the enabler that helps the growth and the sustainment of organizational knowledge.

Kankanhalli et al. (2003) carried a study on the type of organizations and the knowledge management systems used in their organizations viewing from whether they are low volatility or high volatility context (Figure 3). Volatility dimension reflects the rapidity of change in the business environment and thus the extent to which knowledge can be economically reused may be different between organizations that are low or high volatility.

Figure 3: Summary of KM systems and types of organizations

In short, studies on the information technology use in knowledge management has strongly indicated that there is a need to investigate the role of technology and its characteristics in the knowledge 
management practices besides looking at factors such as people and rewarding system. The research focuses on the characteristics and features of POKM, a KM system used in the case company, and the perception of knowledge workers toward POKM in the organization.

\section{RESEARCH FRAMEWORK}

In this research, a IT shared services company was chosen to conduct the investigation. All the participants are knowledge workers who provide IT related services to both internal and external IT users. A total of twenty-three (23) employees from nine (9) departments ranking from junior, mid rank and senior level had been interviewed. Interview content was recorded and analyzed. Questionnaire was designed based on the key points analyzed from the interview content and the KMS Success model is used as the theoretical basis for the design of the questions. The research instrument was pilot tested using $10 \%$ of the employees of the chosen company. The form is revised and reworded after listening to feedback from the comments in the pilot test. A total of fifty-two (57) employees were involved in this exercise. The number of employees varies for each department. The departments that are involved in this survey are: Sales and Marketing, Business Solution, Infrastructure Service and Computer Operations, Application Development and IT Process Management. Objectives of this questionnaire survey are to better understand the employees' perception towards POKM from the Quality, Content Quality, user Interface, POKM functions, POKM satisfaction and perceived POKM benefits. In the questionnaires, a brief description of the survey's objectives is provided to the employees. This is to ensure that that the employees understand the goals of the survey. Most of the questions on the survey form required the employees to rate using the Likert scale of $0-5$.

Interview questions are categorized into three (3) sections: organization, people and technology. With respect to organization, questions on incentive and reward schemes and support from the top management were asked. As for technology, participants were asked the quality, functions/features, and improvements of the POKM. As for people, culture and trust were asked. The purpose of interview is to solicit general perception of the knowledge workers from these three perspectives. In this paper, interview content on perception of POKM will be presented and discussed.

The IT Shared Services Company has a total of seventy (70) employees and the number of forms successfully filled and analysed is fifty-two (52). A reply rate of $74.2 \%$ was obtained. This is an online survey exercise and it was estimated to be completed in less then one month. However, due to difficulties faced during the data collection such as staff on overseas projects and on sick leave, the entire survey duration was extended to three months. The survey form has one hundred (100) questions which also contributed to the long data collection process. The survey data is analysed for consistency and reliability using Cronbach Alpha measurement.

\section{ANALYSIS OF INTERVIEW AND SURVEY DATA}

The interview and survey were analyzed and findings are discussed on the perception of knowledge workers on POKM Quality, Content Quality, User Interface, POKM functions, satisfaction toward POKM and perceived POKM benefits. The interview content will be analyzed and discussed first. Questionnaire survey results will be tabulated and conclusive remarks will be drawn from the analysis.

In the interview, participants were asked on the usage of the features and functions of POKM in their day-to-day activities, four (4) respondents said they used "Search by Keyword" whereas the other four (4) answered that they used "Search by Category". Three (3) respondents answered that they treated POKM as a knowledge repository most of the time. They merely used POKM to deposit documents 
and retrieve documents whenever it is needed. The following is an extract of the reply from one of respondent.

LYY: "I would refer the KMS as a repository of storage storing or knowledge bank for example whenever $i$ need any materials $i$ don't have to wait for my colleagues to get it sent to me instead $i$ can easily download the materials from the system and with this it has definitely speed up my delivery and improves my work productivity".

Six (6) of the respondents used the "Notification" function because it reminded the recipients through email when new posts are available in the system. Many respondents commented that POKM helped them to improve their productivity in their jobs. Some scenarios illustrated by participants showed that POKM has helped them to improve their jobs: tips on new technology, latest tips on productivity, cut down $30 \%$ of customer call-in, well informed decision, higher work efficiency, reduce meeting time, reduce time spent on new staff briefing because new staff are able to access to the latest documentation and SOP easily and timely and latest archive in POKM has helped to provide employees fast delivery service due to ease of document search.

In short, twelve (12) participants expressed interest to have social networking feature to be embedded into POKM. Most of the participants want to see improvement on "Search" function in the future. As for design of the system, intuitive user interface and ease of use are two most wanted features expressed by junior participants during interview. Many suggested that features from popular Social Network Sites (SNS) such as files and photos tagging and intuitively designed user interface are missing in POKM. Most of the participants regretted that POKM has not been improved since it was implemented even numerous recommendations have been proposed to the management.

Questions in the survey form will be analysed for their reliability and consistency; for questions that have a correlation value that is lower then 0.5 will be removed if such removal will significantly improve the reliability and consistency of the factor under study. However, justifications will be provided if such question will be kept due to its importance in the research. The Cronbach coefficient Alpha value for each factor is a good indicator that explains how well the questions designed for that factor. If the Cronbach Alpha value is 0.7 or higher, the questions designed for that factor is considered acceptable. Factor analysis is used to describe how questions that are strongly correlated can be used to explain a factor. Questions that exhibit low inter-correlations will be considered drop. New factor suggested by factor analysis will be investigated if these responses represent a factor that has yet been investigated in this research work.

\subsection{POKM Quality}

The POKM quality is an area that provides insight on how employees perceive the quality of the system. In terms of POKM quality, a number of questions were asked and analyzed. The outcomes of these questions are shown in Figure 4. The chart shows that most of the respondents chose 'Agree' to all the questions related to POKM quality. The numbers of positive responses are more than the negative responses. It is clear that the quality of the POKM is quite good and accepted by most knowledge workers. However, the responses from some of the respondents that chose 'disagree' or 'strongly disagree' on the quality of the POKM should be investigated so that future KM systems has the desired quality improvements. POKM quality is an important factor that will affect system adoption and trust toward the use of the system.

Figure 4: The POKM Quality

Table 3: Questions for POKM Quality 
Table 3 is the questions use to study POKM quality. The standardized Cronbach cooefficient alpha value is 0.945654 which shows that quetsions use to explain POKM quality are highly realiable and consistent. However, Figure 5 shows that Question 11 "Whenever I made a mistake using the system, I could recover easily and quickly" has a low correlation value of 0.1059 . The removal of this question yields a higher standardized Cronbach value of 0.9545 (Figure 6).

Figure 5: Cronbach Coefficient Alpha for POKM Quality

Figure 6: Cronbach Coefficient Alpha after removing Question 11

In short, the investigation outcomes show that the quality of POKM is stable, easy to use and organization of the content is rated good. However, POKM has poor response time and search capability. The finding also highlights that knowledge workers generally agree that this Question 11 is not relevant in the study of POKM quality and the current system doesn't provides an undo or restore function.

\subsection{POKM Content Quality}

A total of 16 questions were used to study the POKM Content Quality (Table 4). The POKM Content Quality intends to understand whether users find that the POKM allows a user to post a piece of knowledge, upload a document and locate content in a timely manner. POKM Content Quality also intend to find out whether cotent is easy to understand, use, consistent and clear. The questions also study whether users find that expert directory in POKM is accurate and helpful to the knowledge workers.

\section{Table 4: Questions for POKM Content Quality}

Figure 7 show that most of the respondents agree that the POKM content is useful to them. They agree that POKM is important and helpful in their works; the system is accessible anytime as well as the recommended solutions in the POKM is useful. In term of search feature, the responses on this question confirm that this is still lacking. A total of 11 respondents chose 'agree' but the number of responses that chose 'disagree' and 'strongly disagree' are much higher. It is clear that the "search" function in POKM needs improvements.

Figure 7: The POKM Content Quality

Figure 8: Cronbach Coefficient Alpha for POKM Content Quality

Figure 8 shows that Cronbach Coefficient Alpha value of 0.914140 indicates that all the questions in the study are reliable and consistent. However, the analysis also found that removal of these three (3) questions can provide a better understanding on POKM Content Quality.

Question 10 "Information, knowledge and files are accessible anytime",

Question 13 "Information, knowledge and files are accessible by anyone" and

Question 15 "KMS provide accurate expert directory (link, yellow pages)"

Figure 9: Cronbach Coefficient Alpha after removing Question 13

Figure 9 shows that the removal of Question 13 has improved the Cronbach value to 0.921955 and the removal of Question 10 and Question 15 will further improve the Cronbach values to 0.922438 and 0.922584 respectively. 
Conclusively, the content organized within POKM is found to be difficult to locate or "search" but most participants agree that knowledge stored in the POKM is helpful, accessible anytime and anywhere and useful for their day-to-day job. The findings also highlight that participants don't think POKM allows content to be accessed anytime by anyone with an accurate expert directory within the system.

\subsection{POKM User Interface}

POKM User Interface investigates the user interface design of POKM. Table 5 contains three (3) questions that were designed to study the perception of participants toward POKM User Interface. Figure 10 depicts the responses of the participants on POKM user interface. It is clear that 14 respondents agree that the POKM user interface is pleasant. However, the responses on POKM functions and capabilities show that ten (10) respondents chose 'agree', eight (8) chose 'disagree' and two (2) chose 'strongly disagree'. It received mixed responses from respondents.

Figure 10: The POKM User Interface

Table 5: Questions for User Interface

Figure 11: Cronbach Coefficient Alpha for POKM User Interface

The Cronbach coefficient alpha value of 0.879419 in Figure 11 shows that all the questions are highly reliable and consistent. However, with the mix responses from respondents shown in Figure 10, the removal of Question 3 "This system has all the functions and capabilities I expect it to have" yields a higher Cronbach value of 0.949069. This means that Question 3 don't help explaining the POKM User Interface in this study. In short, participants agree that the POKM user interface is pleasant and acceptable.

\subsection{POKM Functions}

The POKM Functions study the use of POKM in knowledge creation and sharing among knowledge workers. The findings show that POKM functions enable knowledge networking, sharing, and creation among knowledge workers in the organization. Figure 12 shows that the POKM functions are generally acceptable by the respondents for the purposes of knowledge networking, sharing and creation. All the three (3) questions received positive feedback as most of the respondents rated 'agree'. The analysis shows that the respondents have not fully utilized all the POKM functions yet. However, a large number of respondents chose 'blank' or "not response".

Figure 12: POKM Functions

Table 6: Questions for KMS Functions

Figure 13: Cronbach Coefficient Alpha for POKM Functions

Table 6 lists questions that were designed to investigate POKM Functions. Figure 13 depicts the standardized Cronbach Coefficient Alpha value of 0.903021 shows that all the questions are consistent and reliable. However, removal of Question 3 "The functions and capabilities of the current KMS have strengths of current social networking systems like Facebook and Twitter" produces a higher Cronbach value of 0.915168 . This means that POKM currently don't have the social networking features. In short, the need to deploy Web 2.0 systems such as Facebook in the 
organization or embed social networking features for better $\mathrm{KM}$ practices is an important consideration.

\subsection{POKM User Satisfaction}

POKM User Satisfaction studies different aspects of the current KMS such as efficiency, ease of access, ease of download and support for knowledge sharing and reuse.

In term of user satisfaction toward POKM, Figure 14 shows the satisfactory level of KMS users in terms of the KMS ease of access, ease of download and knowledge reuse. The bar chart shows that majority of the employees are satisfied with the ease of access and knowledge reuse whereas for the KMS efficiency and effectiveness as well as ease of download, the majority of the respondents tend to remain neutral or 'blank' and lower 'agree' rate. This shows that the efficiency and effectiveness of the KMS may need some improvements. However, users generally are satisfied with the ease of access and reuse of knowledge contains in POKM.

Figure 14: User Satisfaction towards POKM

\section{Table 7: Questions for POKM User Satisfaction}

Table 7 illustrates the questions designed to study the POKM satisfaction among knowledge workers. The responses of the survey is analyzed using standardized Cronbach cooefficient aplha with a value of 0.924014 which shows that the satisfaction towards POKM has high realiability and consistency (Figure 15). We also found Question 5 "I am satisfied with the KMS ease of download" is a non contributing item in this study. The removal of this item has improved the Cronbach value to 0.935730. This is a clear indication that knowledge workers generally don't find that ease of download is a helpful feature in their day-to-day job.

Figure 15: Cronbach Alpha for POKM User Satisfaction

In short, besides POKM efficiency and effectiveness, the download feature of POKM needs some improvements to get the acceptance of the knowledge workers. As for ease of access, knowledge access and reuse and meeting information processing needs, participants satisfy with the POKM currently.

\subsection{Perceived POKM Benefits}

The perceived POKM benefits examine benefits of POKM from the user's point of view. Figure 16 tabulated responses of participants on perceived POKM benefits. Three (3) questions (Table 8) were used to study users' perception toward perceived POKM benefits. The first question studied how POKM has helped the users in acquiring new knowledge and innovative ideas. The second question asked about how POKM has helped the users effectively manage and store knowledge and the last question examined how POKM has helped the users to accomplish task more efficiently. Based on the respondents' answers, majority of the respondents agree that POKM has helped them with seventeen (17) respondents "agree" with Question 1, nineteen (19) respondents "agree" to Question 12 and fifteen (15) respondents "agree" to Question 3. From responses of these three questions, they show that most users use POKM to manage and store their knowledge. Participants also agree that POKM is a knowledge enabler that facilitates acquiring of new knowledge and innovative ideas, for managing and storing knowledge, and for accomplishing tasks more efficiently.

Figure 16: Perceived POKM Benefits 
Table 8: Sample questions Perceived KMS Benefits

From the analysis, one noticeable finding is the second highest responses from participants on Question 1, 2 and 3 that chose "neither agree nor disagree". The Cronbach value of 0.865425 (Figure 17) confirms this observation. This is due to the number of responses on "Agree" and "Strong Agree" compare to responses on "neither agree nor disagree", "Disagree", "Strong disagree" are rather low.

Figure 17: Cronbach Alpha for perceived POKM benefits

Question 1 "KMS helps me to acquire new knowledge and innovative ideas" has a low 0.568903 indicates that knowledge workers generally don't think POKM is able to generate new knowledge or innovative ideas. The removal of this question has shown a higher standardized Alpha value of 0.865849 (Figure 17) toward perceived POKM benefit. This confirms that knowledge workers who are using POKM don't feel that the system helps them to generate of new innovative ideas within the organization. This is seriously a serious drawback and further investigation is required in order to understand the knoweldge quality in POKM and the contributing attitude among knowledge workers that bring such a negative response from the outcomes of the study.

Conclusively, most participants use POKM to manage and store their knowledge but they highlight that current POKM doesn't help generation of new knowledge and innovatives ideas. More importantly, low percentage of participants chose "Agree" and "Strongly Agree" on POKM facilitates "acquiring new knowledge and innovative ideas", "effectively manage and store knowledge that I need" and "enable me to accomplish tasks more efficiently" clearly show that many don't support such claims.

\section{CONCLUSION}

The investigation of the case company through research activities such as interview and questionnaire survey has provided a good level of understanding on several aspects of POKM: functions, quality, content quality, user interface, user satisfaction and perceived benefits. Content from interview and outcomes of the questionnaire survey has given researchers better conclusive findings on the perception of knowledge workers toward POKM in the organization. The following discussion summarizes some important recommendations obtained from the analysis of the responses from the knowledge workers in the organization.

The analysis of the research findings has pointed out that the quality of POKM is stable, easy to use and organization of the content is rated good. However, POKM has poor response time and search capability. The content is found to be difficult to locate in the POKM but most participants agree that knowledge stored in the POKM is helpful, can be accessed anytime and anywhere and useful for their day-to-day job. As for the user interface, POKM is not very pleasant to use with a weak set of functions and features. For user satisfaction towards POKM, it is shown that users are not satisfied with the efficiency and effectiveness of the systems. However, employees generally are satisfied with the ease of access and reuse of knowledge contains in POKM. In term of perceived POKM benefits, users agree that POKM is an enabler for acquiring new knowledge and innovative ideas, managing and storing knowledge, and accomplishing tasks more efficiently. Lastly, knowledge users agree that POKM functions enable knowledge networking, sharing, and creation in the organization.

Perhaps, the organization should take into consideration of applying the concept of an ecology model for KM systems where this model includes knowledge distribution, interaction, competition and evolution in per say to interact with each other and to be able to maintain a healthy ecological knowledge environment in the organization. 


\section{References}

Argote, L. (1999), Organizational learning: Creating, retaining and transferring knowledge, Boston, MA: Kluwer Academics Publishers.

Borghoff, U. M. and Pareschi, R. (1997), "Information Technology for Knowledge Management", Journal of Universal Computer Science, Vol. 3 Issue 8, pp. 835-842.

Dalkir K. (2005), Knowledge Management in Theory and Practice, Elsevier, UK.

Davenport, T. H. (2005), Thinking for Living, Harvard Business School Publishing.

Davenport, T. H. (1997), "Building Successful Knowledge Management Projects" available at: http://www.providersedge.com/docs/km_articles/Building_Successful_KM_Projects.pdf (Accessed on 21 ${ }^{\text {st }}$ October 2012)

Dell O. C. and Hubert C. (2011), The New Edge in Knowledge, John Wiley \& Sons, Inc., Hoboken, New Jersey.

Drucker, P. F. (1954), Landmarks of Tomorrow. A report on the New 'Post-Modern' World, Transaction Publisher London.

Edna, P., Tuvya R. (2011), The complete guide to Knowledge Management, A strategic plan to leverage your organization's Intellectual Capital, John Wiley \& Sons, Inc., Hoboken, New Jersey.

Farkas, M. F., Torok, L.G. (2011), “Knowledge Workers, Competencies, Virtuality and Management”, Polish Journal of Management studies, Vol. 4.

Frank M. (2008), A Knowledge Management System: A Discourse, Knowledgeone Corporation.

Grant, R. M. (1996), "Prospering in dynamically competitive environments: Organizational capability as knowledge integration“, Organization Science, Vol. 7 pp. 375-387.

Kankanhalli, A., Tanudidjaja, F., Sutanto, J. and Tan, Bernard C. Y. (2003), "Role of Information Technology in Successful Knowledge Management Initiatives", Communications of the ACM, Vol. 46 Issue 9, pp. 69-73.

Knowledge Workers (2013), available at: http://www.referenceforbusiness.com/management/IntLoc/Knowledge-Workers.html, encyclopedia of Business $2^{\text {nd }}$ ed (Accessed on 12nd June 2013)

Lindvall, M., Rus, I. and Sinha, S. S. (2003), "Technology Support for Knowledge Management", Advances in Learning Software Organizations, Lecture Notes in Computer Science, Vol. 2640, pp 94-103.

McGinn, D. and Raymond, J., "Workers of the World, Get Online", Newsweek (Winter 1997-98) Extra Millennium Issue: 32.

Mladkova, L. (2011), “Management of Knowledge Workers”, Economics and Management:2011.16

Nonaka I. and Takeuchi H. (1995), The knowledge creating company: how Japanese companies create the dynamics of innovation, New York: Oxford University Press.

Prince, W. W. (2011), Knowledge Worker, Encyclopedia of Business, $2^{\text {nd }}$ Ed.

Pfeiffer J. and Sutton R. (1999), The knowing -doing gap: How smart companies turn knowledge into action, Boston: Harvard Business School Press.

Reboul, C. (2006), "Managing knowledge workers: the KWP matrix", in Conference Proceedings MOMAN 06, Prague. 
Rikard L. and Christopher W. (2000), "Features Missing in Action: Knowledge Management Systems in Practice", in ECIS 2000 Proceedings.

Rogoski, R. R. (1999), “Knowledge Workers Top Organization Assets”, Triangle Business Journal, No 19.

Spiral, J. B. (2008), “Knowledge worker: Do you relate?”, available at: http://www.kmworld.com/articles/news/news-analysis/knowledge-worker-do-you-relate-40808.aspx (accessed 12 June 2013)

Suzanne, Z. (2003), "The role of technology in Knowledge Management: trends in the Australian corporate environment", Journal of Information \& Knowledge Management, Vol. 02, Issue 02, pp. 165-181.

Toffler, A. (1990), Powershift: Knowledge, Wealth and Violence at the Edge of the $21^{\text {st }}$ Century, Bantam Books.

Vinson, J. (2009), "Another definition of Knowledge Worker", available at: http://blog.jackvinson.com/archives/2005/02/06/another_definition_of_knowledge_worker.html (Accessed on $21^{\text {st }}$ October 2012)

Wernerfelt, B. (1984), “A resource based view of the firm“, Strategic Management Journal, Vol. 5, pp. 171-181.

Wiig, K. M. (1994), Knowledge management foundations: Thinking about thinking: how people and organizations create, represent, and use knowledge, Schema Pr.

Wolff, E. N., (2006), “The Growth of Information Workers in the US Economy, 1950-2000”, Economic Systems Research, Vol. 18, Issue 3, pp. 221-255. 